\title{
Effectiveness of Teaching Program on Critical Care Nurses' Performance during Endotracheal Suctioning in the Intensive Care Units in Syria
}

\author{
Yaser Adnan Abo Jeesh
}

College of Applied Medical Sciences, Alzaiem Alazhari University, Sudan Elham Fath-Elalium Mohammed Khalid

College of Medicine, Alzaiem Alazhari University, Sudan

Ishraqa Mohammed Ahmed Elbashier

College of Applied Medical Sciences, Alzaiem Alazhari University, Sudan

Doi:10.19044/esj.2021.v17n34p190

Submitted: 14 July 2021

Accepted: 23 August 2021

Published: 30 September 2021
Copyright 2021 Author(s)

Under Creative Commons BY-NC-ND 4.0 OPEN ACCESS

\section{Cite As:}

Abo Jeesh Y.A., Mohammed Khalid E.F-E. \& Ahmed Elbashier I.M. (2021). Effectiveness of Teaching Program on Critical Care Nurses' Performance during Endotracheal Suctioning in the Intensive Care Units in Syria. European Scientific Journal, ESJ, 17(34), 190.

https://doi.org/10.19044/esj.2021.v17n34p190

\section{Abstract}

Background: The Intensive Care Unit (ICU) is a unit in the hospital which provides intensive care for critically ill or injured patients and is staffed with specially trained medical personnel and has equipment that allows for continuous monitoring and life support. Moreover, critical care nurses (CCNs) should have strong analytical, interpersonal, and decision-making skills. Also they need to continuously improve their knowledge, skills, and safe practice to deliver safe and effective care to their patients.

Objectives: This study aimed to assess the effect of the teaching program on CCNs performance during endotracheal suctioning.

Design: The quasi-experimental design was used in this study.

Methods: The study was conducted from June to September 2020. This study was conducted to assess the effect of the teaching program on nurse's performance during endotracheal suctioning in the critical care units at Al-Assad University Hospital, Damascus. All available registered nurses (48 nurses) who were working in the previous ICUs during the period of data collection were included in this study. An observational checklist sheet was developed by the researcher after reviewing the related literature. The duration 
of data collection was about three months, and each nurse was observed once for each procedure during different shifts. Based on the nurses' need according to their performance during the initial assessment, the researcher developed and designed the teaching program. This program continued for two weeks consisting of four phases and contains workshop-practices (8hours) per day and educational pamphlet handout. The workshop practice consists of lectures, group discussion, and training scenarios. Every nurse must attend the training sessions daily, at least one hour.

Results: The results showed that the level of knowledge and practice of the studied nurses in endotracheal suction was average and poor before the teaching program and the nurse's level improved after the program. There was a variation of improvement regarding the nurses age, qualification, and experience. The best performance was for nurses with age group between 2024 years, nurses with a master degree, and nurses with less than five years of experience. Overall, this study found a statistically significant relationship before and after the implementation of the educational program $(\mathrm{p}<0.001)$.

Conclusion: There has been an obvious improvement of nurses' knowledge and performance after the teaching program in relation to age, qualifications, and experience in all selective procedures. It is essential to help the nurses to expand their knowledge and practices to provide a high quality of care and promote patient safety.

Keywords: Intensive Care Unit, Patient, Quality

\section{Introduction}

The intensive care unit (ICU) is a specially staffed and equipped, separate, and self-contained section of the hospital for the management of patients with life threatening or potentially life-threatening conditions (Hamilton \& Shepley, 2010). The nurse's role usually includes clinical assessment, diagnosis, and an individualized plan of expected treatment outcomes for each patient (Stayt, 2007; Ghorbanpoo Jouybari et al., 2018). Critically ill patients are often unable to eat because of endotracheal intubation and the need for mechanical ventilation (Ghorbanpoor Jouybari et al., 2018).

The conventional sterile suctioning technique involves the use of at least an individual sterile single use suction catheter per each suctioning episode. Consequently, suctioning catheter is the single biggest item of expenditure consumables in ICU. From anecdotal reports, it was obvious that in some units, the disposable suction catheter may be reused for multiple episodes of suctioning. Although considerable cost saving would result from this change in practice, concerns were raised regarding its safety, and many nurses were reluctant to implement this practice (Kandeel \& Tantawy, 2012; Özden \& Görgülü, 2012; Jansso Ala-Kokko et al., 2013). 
Many of the critically ill patients may require intubation by the placement of an endotracheal or tracheostomy tube to protect the airway from aspiration, facilitate the removal of tracheobronchial secretions, provide positive pressure ventilation, and relieve airway obstruction (Hyzy Manaker et al., 2017; Cabrini Landoni et al., 2018).

Tracheal suctioning is a necessary intervention in caring for the intubated patient, and it is not a benign one. It is associated with various complications such as hypoxemia, cardiac dysrhythmias, nosocomial respiratory tract infection, pneumonia, laryngeal spasm, trauma, atelectasis, and in extreme cases, death. Nosocomial respiratory tract infection and pneumonia are considered as two of the most serious complications associated with suctioning (Griesdale Bosma et al., 2008; Simpso Ross et al., 2012; Higgs McGrath et al., 2018).

Although tracheal suctioning is an essential part of care for intubated patients that may be required between 3 and 24 times or more a day, it is considered as a significant route of bacterial entry to the lower respiratory tract causing subsequently respiratory tract infection and pneumonia. Therefore, many authors recommended using a sterile suctioning technique as a precautionary measure. Different actions such as using sterile gloves, catheters, and saline (to clear mucus from the catheter) are suggested (Özden \& Görgülü, 2012; Jansson Ala-Kokko et al., 2013; Abdallh, 2018). The utility of tracheal suctioning on the prevention of hospital-acquired pulmonary infections and mortality in the ICU has been well studied in the past. Nowadays, many researches indicated that tracheal suctioning improves mucus clearance in COVID-19 pneumonia (Farooqi Morgan et al., 2020).

\section{Significant of the Study}

Critically ill patients admitted to an ICU experience, on average, 1.7 medical errors each day, and many patients suffer a potentially life-threatening error during their stay (Camiré Moyen et al., 2009; Gracia Serrano et al., 2019).

Nurses and all other health care professionals sometimes make mistakes in providing their care services regardless of their level of expertise, knowledge, and precision. Nursing errors can occur at any point in time during nursing activities and procedures, and the outcomes may be subtle or severe (Peyrovi, Nikbakht Nasrabadi et al., 2016).

Like other parts of the world, there are a negative patient health and healthcare outcomes in Syria. Therefore, special attention should be paid to the clinical skills and knowledge of nurses working in ICUs (Rezaee Ghaljeh et al., 2020). Therefore, this study was conducted to assess the effect of an educational program on nurses' practices regarding the implementation of patient care and safety measures in the intensive care units in Syria. 


\section{Methods}

The quasi-experimental design was used in this study (non-random sample and doesn't have control) to determine the relationship and the effect of the teaching program on the improvement of nurses' performance during the nursing interventions. This study was conducted to assess the effect of the teaching program on nurses’ performance during endotracheal suctioning in the intensive care units at Al-Assad University Hospital, Damascus. All available registered nurses (48 nurses) who were working in the intensive care units during the period of data collection were included in this study.

\section{Ethical Considerations}

- Official permission was granted from the Al-Assad University Hospital, Damascus after providing an explanation of the study aim to the manger and head of intensive care unit.

- The observational checklist sheet was developed by the researcher after reviewing the related literature.

- Nurses' characteristics were recorded once at the beginning of the data collection.

- Each nurse was observed once for each procedure during different shifts.

- The duration of data collection was about three months.

- The survey formats were distributed via the investigator himself with a cover letter indicating the purpose of the study, confidentiality procedures, and hospital review approval.

- Nurses were assured that there will be no harm or risk, or any discomfort caused by their participation.

\section{Tools}

The tool used in this study was developed by the researcher, and it is divided into two parts: (1) Demographic data of the studied nurses (Table 1), and (2) The observational checklist (Table 2) to observe the nurses' performance regarding the implementation of patient care and safety measures during endotracheal suctioning procedure. Thus, it was developed by the researcher based on extensive review of the literature (Roberts, 2017; Jones \& Fix, 2019; Nunnery, 2019; Smith, 2019; Wilkinson Treas et al., 2019). The tool was translated into Arabic Language. A pilot study was conducted on 5 nurses to test the tool. Appropriate modifications were performed such as changing some words into Arabic version.

The safety measures observational checklist was tested for its reliability by using interrated reliability, whereas three experts of the critical care nursing field assessed the tool for its applicability. The reliability 
coefficients were: $(r)=0.96$ for the safety measures observational checklist. Cronbach's alpha coefficient 0.84

\section{Data Collection}

Data collection was conducted from June 2020 to September 2020. The data collection went through four stages: (1) Assessment: Every nurse was observed once for each procedure at the beginning of data collection to determine the nurses' weaknesses, (2) Planning: The teaching program was developed based on the nurses' needs, (3) Intervention: Implementing the program through the power point presentations and training sessions, (4) Reassessment: Reassess the nurses' performance after implementing the teaching program.

\section{Statistical Analysis}

The data were analysed using the Statistical Package for the Social Science (SPSS version 20.0). Qualitative data were described using number and percent (Armonk, NY: IBM Corp). The Kolmogorov-Smirnov test was used to verify the normality of distribution. Quantitative data were described using range (minimum and maximum), mean, and standard deviation. Significance of the obtained results was judged at the $5 \%$ level.

\section{Educational Program}

The program was already designed in Arabic language. The program is aimed at improving the nurses' knowledge and practices as is related to the endotracheal suctioning by teaching them the updated knowledge power point presentations. Also, it allows them to improve their performance through training sessions on manikins.

The program is to run for two weeks, and every nurse must attend the training sessions daily for one hour at least each day. It consists of 8 hours workshop per day to deliver the power point presentations and the training sessions.

The program was created and developed through four phases. During the first phase, the researcher assessed the nurses' performance by using the designed and developed endotracheal suctioning checklist. During the second phase, the researcher developed and implemented the teaching program based on the nurses' needs according to their performance during the initial assessment. For the third phase, the researcher delivered the program through power point presentations, demonstrations, and training sessions to provide the nurses with related knowledge and to improve nurses' performance. Finally, for the fourth phase, the researcher reassessed the nurses' performance after the program to determine the nurses' improvement. 


\section{Results}

The total number of the studied nurses was 48 nurses with a mean age of 28 years.

In relation to age, 17 nurses (more than 35\%) of the studied nurses were from 25-29 age group, while there was an equal number of nurses with both age groups from 20-24 and from 30-35 (14 nurses for each) (29.2\%). 3 nurses were more than 35 years (6.3\%).

Regarding to the qualifications, the majority of the studied nurses, 38 nurses (about 80\%) have a diploma degree, 7 nurses (about 15\%) have a bachelor degree, and 3 nurses (about 6\%) have a master degree.

Regarding to the years of experience, 23 nurses (47.9\%) have less than 5 years of experience, 17 nurses (35.4\%) have between five to ten years of experience, and 8 nurses (16.7 \%) have more than 10 years of experience. The mean of nurses' experience was 6 years (Table 1 ).

Table 1. The characteristics of the studied nurses

\begin{tabular}{|c|c|c|}
\hline Demographic data & No. & \% \\
\hline Age of the nurse & \multicolumn{2}{|c|}{} \\
\hline $20-24$ & 14 & 29.2 \\
\hline $25-29$ & 17 & 35.4 \\
\hline $30-35$ & 14 & 29.2 \\
\hline Above 35 & 3 & 6.3 \\
\hline Mean \pm SD. & \multicolumn{2}{|c|}{$28.02 \pm 5.51$} \\
\hline Qualification of the nurse & 38 & 79.2 \\
\hline Diploma & 7 & 14.6 \\
\hline Bachelor & 3 & 6.3 \\
\hline Master & \multicolumn{2}{|}{} \\
\hline Experience of the nurse in ICU & 23 & 47.9 \\
\hline Less than 5 years & 17 & 35.4 \\
\hline 5- 10 years & 8 & 16.7 \\
\hline More than 10 years & \multicolumn{2}{|c}{$6.27 \pm 4.53$} \\
\hline Mean \pm SD. & \multicolumn{2}{|c|}{} \\
\hline
\end{tabular}

\section{The Implementation of Patient Care and Safety Measures of the Studied Nurses}

The result above shows that the nurses disregarded and didn't implement most of the steps given in this procedure in the correct way before the educational program. The total steps of this procedure were thirty-four with total scores of 136 . The nurses didn't perform twenty-eight steps correctly at all, while the percentage of the nurses that performed the other six steps correctly ranged from 2.1-33.3\%. It was noticed that all nurses ignored and didn't perform step number 11 and 15 at all before the program, and they improved after the program. Anyway, the results showed there were variations of nurses' improvement after the teaching program in all steps. The percentage 
of the nurses that performed the steps correctly ranged from 4.2- 91.7\%. In addition, the nurses' scores were varied from 55-103 with mean of $72.81 \pm$ 11.37 before the program to $97-131$ with mean of $117.73 \pm 7.49$ after the program.

Table 2. The description and implementation of patient care and safety measures of the studied nurses according to tracheal suctioning steps before and after the educational program

\begin{tabular}{|c|c|c|c|c|c|c|c|c|c|c|c|c|c|c|c|c|}
\hline \multirow{4}{*}{ The checklist of endotracheal suctioning } & \multicolumn{16}{|c|}{ Frequency $(\mathrm{N}-48)$} \\
\hline & \multicolumn{8}{|c|}{ Before an educational program } & \multicolumn{8}{|c|}{ After an educational program } \\
\hline & \multicolumn{2}{|c|}{ Not done } & \multicolumn{2}{|c|}{$\begin{array}{c}\text { Done } \\
\text { incorrectly }\end{array}$} & \multicolumn{2}{|c|}{$\begin{array}{l}\text { Need more } \\
\text { practice }\end{array}$} & \multicolumn{2}{|c|}{$\begin{array}{c}\text { Done } \\
\text { correctly }\end{array}$} & \multicolumn{2}{|c|}{ Not done } & \multicolumn{2}{|c|}{$\begin{array}{c}\text { Done } \\
\text { incorrectly }\end{array}$} & \multicolumn{2}{|c|}{$\begin{array}{c}\text { Need } \\
\text { more } \\
\text { practice }\end{array}$} & \multicolumn{2}{|c|}{$\begin{array}{c}\text { Done } \\
\text { correctly }\end{array}$} \\
\hline & No. & $\%$ & No. & $\%$ & No. & $\%$ & \begin{tabular}{l|l}
$\mathbf{N}$ \\
$\mathbf{0 .}$
\end{tabular} & $\%$ & No. & $\%$ & No. & $\%$ & No. & $\%$ & No. & $\%$ \\
\hline Identify the patient & 8 & 16.7 & 11 & 22.9 & 13 & 27.1 & 16 & 33.3 & 0 & 0.0 & 4 & 8.3 & 12 & 25.0 & 32 & 66.7 \\
\hline Prepare equipment & 0 & 0.0 & 25 & 52.1 & 23 & 47.9 & 0 & 0.0 & 0 & 0.0 & 0 & 0.0 & 24 & 50.0 & 24 & 50.0 \\
\hline Wash hands & 10 & 33.3 & 20 & 41.7 & 12 & 25.0 & 0 & 0.0 & 0 & 0.0 & 0 & 12.5 & 30 & 62.5 & 12 & 25.0 \\
\hline Explain proceduse to the patient or to the family & 11 & 22.9 & 30 & 62.5 & 7 & 14.6 & 0 & 0.0 & 0 & 0.0 & 8 & 16.7 & 23 & 47.9 & 17 & 35.4 \\
\hline $\begin{array}{l}\text { Assess patient for signs of respiratory distress such as nasal } \\
\text { flaring, retractions or grunting and also assess the patient's } \\
\text { lung sounds }\end{array}$ & 21 & 43.8 & 22 & 45.8 & 5 & 10.4 & 0 & 0.0 & 0 & 0.0 & 5 & 10.4 & 25 & 52.1 & 18 & 37.5 \\
\hline Assess oxygen saturation level & 24 & 500 & 23 & 479 & 1 & 2.1 & 0 & 00 & 2 & 42 & 3 & 63 & 20 & 417 & 23 & 479 \\
\hline Assess appropriate suction catheter depth & 0 & 0.0 & 19 & 39.6 & 27 & 56.3 & 2 & 4.2 & 0 & 0.0 & 0 & 0.0 & 9 & 18.8 & 39 & 81.3 \\
\hline $\begin{array}{l}\text { Position the patient and place a towel across the patient's } \\
\text { chest }\end{array}$ & 0 & 0.0 & 23 & 47.9 & 25 & 52.1 & 0 & 0.0 & 0 & 0.0 & 1 & 2.1 & 11 & 22.9 & 36 & 75.0 \\
\hline $\begin{array}{l}\text { Turn suction to appropriate negative pressure. Place the } \\
\text { connocting tubing in a convenicnt location }\end{array}$ & 0 & 0.0 & 15 & 31.3 & 31 & 64.6 & 2 & 4.2 & 0 & 0.0 & 0 & 0.0 & 11 & 22.9 & 37 & 77.1 \\
\hline $\begin{array}{l}\text { Put on a disposable clean glove and occlude the end of the } \\
\text { connecting tubing to check suction pressure }\end{array}$ & 11 & 22.9 & 14 & 29.2 & 23 & 47.9 & 0 & 0.0 & 0 & 0.0 & 4 & 8.3 & 18 & 37.5 & 26 & 54.2 \\
\hline $\begin{array}{l}\text { Place the resuscitation bag connected to oxygen within } \\
\text { convenient reach }\end{array}$ & 47 & 97.9 & 1 & 2.1 & 0 & 0.0 & 0 & 0.0 & 1 & 2.1 & 11 & 22.9 & 34 & 70.8 & 2 & 4.2 \\
\hline $\begin{array}{l}\text { Open sterile suction package using aseptic technique. The } \\
\text { open wrapper becomes a sterile field to hold other supplies }\end{array}$ & 0 & 0.0 & 45 & 93.8 & 3 & 6.3 & 0 & 0.0 & 0 & 0.0 & 0 & 0.0 & 30 & 62.5 & 18 & 37.5 \\
\hline $\begin{array}{l}\text { Carefully remove the sterile container, touching only the } \\
\text { outside surface }\end{array}$ & 0 & 0.0 & 25 & 52.1 & 23 & 47.9 & 0 & 0.0 & 0 & 0.0 & 0 & 0.0 & 17 & 35.4 & 31 & 64.6 \\
\hline Set it up on the work surface and pour sterile saline into it & 0 & 0.0 & 12 & 25.0 & 36 & 75.0 & 0 & 0.0 & 0 & 0.0 & 1 & 2.1 & 13 & 27.1 & 34 & 70.8 \\
\hline $\begin{array}{l}\text { Put on face shield or goggles, mask, and sterile gloves The } \\
\text { dominant hand will manipulate the catheter and must remain } \\
\text { sterile }\end{array}$ & 48 & 1000 & 0 & 00 & 0 & 00 & 0 & 00 & 2 & 42 & 16 & 333 & 28 & 583 & 2 & 42 \\
\hline $\begin{array}{l}\text { With dominant hand glove, pick up sterile catheter. Pick up } \\
\text { the connecting tubing with the non-dominant hand and } \\
\text { connect suction catheter }\end{array}$ & 0 & 0.0 & 35 & 72.9 & 13 & 27.1 & 0 & 0.0 & 0 & 0.0 & 2 & 4.2 & 28 & 58.3 & 18 & 37.5 \\
\hline
\end{tabular}




\begin{tabular}{|c|c|c|c|c|c|c|c|c|c|c|c|c|c|c|c|c|}
\hline \multirow{4}{*}{ The checklist of endotracheal suctioning } & \multicolumn{16}{|c|}{ Frequency $(\mathrm{N}=48)$} \\
\hline & \multicolumn{8}{|c|}{ Before an educational program } & \multicolumn{8}{|c|}{ After an educational program } \\
\hline & \multicolumn{2}{|c|}{ Not done } & \multicolumn{2}{|c|}{$\begin{array}{c}\text { Done } \\
\text { incorrectly }\end{array}$} & \multicolumn{2}{|c|}{$\begin{array}{c}\text { Need } \\
\text { more } \\
\text { practice }\end{array}$} & \multicolumn{2}{|c|}{$\begin{array}{c}\text { Done } \\
\text { correctly }\end{array}$} & \multicolumn{2}{|c|}{ Not done } & \multicolumn{2}{|c|}{$\begin{array}{l}\text { Done } \\
\text { incorrectly }\end{array}$} & \multicolumn{2}{|c|}{$\begin{array}{c}\text { Need } \\
\text { more } \\
\text { practice }\end{array}$} & \multicolumn{2}{|c|}{$\begin{array}{c}\text { Done } \\
\text { correctly }\end{array}$} \\
\hline & No. & $\%$ & No. & $\%$ & No. & $\%$ & No. & $\%$ & No. & $\%$ & No. & $\%$ & No. & $\%$ & No. & $\%$ \\
\hline $\begin{array}{l}\text { Moisten the catheter by dipping it into the container of sterile } \\
\text { saline, Occlude Y-tube to check suction. }\end{array}$ & 0 & 0.0 & 15 & 31.3 & 33 & 58.8 & 0 & 0.0 & 0 & 0.0 & 2 & 4.2 & 13 & 27.1 & 33 & 68.8 \\
\hline $\begin{array}{l}\text { Hyperventilate the patient using your non-dominant hand and a } \\
\text { manual resuscitation bag, and delivering three to six breaths or use } \\
\text { the sigh mechanism on a mechanical ventilator. }\end{array}$ & 16 & 33.3 & 30 & 62.5 & 2 & 4.2 & 0 & 0.0 & 1 & 2.1 & 6 & 12.5 & 29 & 60.4 & 12 & 25.0 \\
\hline $\begin{array}{l}\text { Open the adapter on the mechanical ventilator tubing, or remove } \\
\text { the manual resuscitation bag with your non-dominant hand. }\end{array}$ & 0 & 0.0 & 34 & 70.8 & 14 & 29.2 & 0 & 0.0 & 0 & 0.0 & 0 & 0.0 & \begin{tabular}{l|l}
10 \\
\end{tabular} & 20.8 & 38 & 79.2 \\
\hline $\begin{array}{l}\text { Using your cominant hand, gently and quickly insert the catheter } \\
\text { into the trachea. }\end{array}$ & 0 & 0.0 & 16 & 33.3 & 31 & 54.6 & 1 & 2.1 & 0 & 0.0 & 0 & 0.0 & 16 & 33.3 & 32 & 66.7 \\
\hline $\begin{array}{l}\text { Apply suction by intermittently occluding the Y-proton, the } \\
\text { catheter with the thumb of your non-dominant hand, and gently } \\
\text { rotate the catheter as it is being,withdrawn. }\end{array}$ & 0 & 0.0 & 31 & 64.6 & 17 & 35.4 & 0 & 0.0 & 0 & 0.0 & 3 & 6.3 & 17 & 35.4 & 28 & 58.3 \\
\hline $\begin{array}{l}\text { Hyperventilate the patient using your non-dominant hand and a } \\
\text { manual resuscitation bag, and delivering three to six breaths. }\end{array}$ & 14 & 29.2 & 32 & 66.7 & 2 & 4.2 & 0 & 0.0 & 0 & 0.0 & 0 & 0.0 & 24 & \begin{tabular}{l|}
50.0 \\
\end{tabular} & 24 & 50.0 \\
\hline $\begin{array}{l}\text { Replace the oxygen delivery device, if applicable, using your non- } \\
\text { dominant hand and have the patient take several deep breaths. }\end{array}$ & 20 & 41.7 & 20 & 41.7 & 8 & 16.7 & 0 & 0.0 & 0 & 0.0 & 2 & 4.2 & 11 & 22.9 & 35 & 72.9 \\
\hline $\begin{array}{l}\text { If the patient is mechanically ventilated, close the adapter on the } \\
\text { mechanical rentilator tubing, or replace the ventilator tubing and } \\
\text { use the sigh mechanism on a mechanical ventilator. }\end{array}$ & 0 & 0.0 & 35 & 72.9 & 13 & 27.1 & 0 & 0.0 & 0 & \begin{tabular}{l|l}
0.0 \\
\end{tabular} & 2 & 4.2 & 20 & \begin{tabular}{|l|}
41.7 \\
\end{tabular} & 26 & 54.2 \\
\hline $\begin{array}{l}\text { Flush catheter with saline. Assess the effectiveness of suctioning } \\
\text { and repeat as needed, and according to patient's tolerance. }\end{array}$ & 11 & 22.9 & 22 & 45.8 & 15 & 31.3 & 0 & 0.0 & 0 & \begin{tabular}{l|l}
0.0 \\
\end{tabular} & 1 & 2.1 & 11 & 22.9 & 36 & 75.0 \\
\hline $\begin{array}{l}\text { Allow at least a } 30 \text {-second to } 1 \text {-minute interval if additional } \\
\text { suctioning isneeded. }\end{array}$ & 9 & 18.8 & 21 & 43.8 & 18 & 37.5 & 0 & 0.0 & 0 & \begin{tabular}{l|l}
0.0 \\
\end{tabular} & 0 & 0.0 & 4 & 8.3 & 44 & 91.7 \\
\hline Assist patient to a comfortable position. & 5 & 10.4 & 20 & 41.7 & 23 & 47.9 & 0 & 0.0 & 1 & 2.1 & 0 & 0.0 & 20 & 41.7 & 27 & 56.3 \\
\hline Raise bed rail and place bed in the lowest position. & 13 & 27.1 & 29 & 60.4 & 6 & 12.5 & 0 & 0.0 & 2 & 4.2 & 3 & 6.3 & 22 & 45.8 & 21 & 43.8 \\
\hline Assess the patient's respiratory status. & 16 & 33.3 & 30 & 62.5 & 2 & 4.2 & 0 & 0.0 & 0 & 0.0 & 2 & 4.2 & 28 & 58.3 & 18 & 37.5 \\
\hline Perform oral hygiene after suctioning. & 14 & 29.2 & 26 & 54.2 & 8 & 16.7 & 0 & 0.0 & 3 & 6.3 & 0 & 0.0 & 20 & 41.7 & 25 & 52.1 \\
\hline Dispose of catheter and container with solution. & 0 & 0.0 & 27 & 56.3 & 18 & 37.5 & 3 & 6.3 & 0 & 0.0 & 0 & 0.0 & 11 & 22.9 & 37 & 77.1 \\
\hline Remove gloves, face shield or goggles, and mask & 14 & 29.2 & 21 & 43.8 & 13 & 27.1 & 0 & 0.0 & 13 & 27.1 & 2 & 4.2 & 4 & 8.3 & 29 & 60.4 \\
\hline Wash hands. & 5 & 10.4 & 30 & 62.5 & 13 & 27.1 & 0 & 0.0 & 0 & 0.0 & 3 & 6.3 & 21 & 43.8 & 24 & 50.0 \\
\hline Documentation. & 5 & 10.4 & 18 & 37.5 & 17 & 35.4 & 8 & 16.7 & 0 & 0.0 & 0 & 0.0 & 14 & 29.2 & 34 & 70.8 \\
\hline \multicolumn{17}{|l|}{ Total score of Suctioning (34-136) } \\
\hline Min.-Max. & \multicolumn{8}{|c|}{$55.0-103.0$} & \multicolumn{8}{|c|}{$97.0-131.0$} \\
\hline Mean \pm SD & \multicolumn{8}{|c|}{$72.81 \pm 11.37$} & \multicolumn{8}{|c|}{$117.73 \pm 7.49$} \\
\hline$t(p)$ & & & & & & & & $.068^{*}$ & $0.00 \mathrm{~s}$ & & & & & & & \\
\hline
\end{tabular}

t: Paired t-test; p: p value for comparing between Before and After *: Statistically significant at $\mathrm{p} \leq 0.05$

In regards to the nurses' age, the result shows that the scores of the nurses with age group between 20-24 varied from 68-81 out of 136 before the program to 114-122 after the program.

The scores of the nurses with age group (25-29) ranged from 61-103 before the program to $113-131$ after the program.

The nurses with age group ranging from 20-24 and 25-29 were the best before and after the program.

The scores of the nurses with age group (30-35) ranged from 57-68 before the program to 104-128 after the program.

The scores for nurses with more than 35 years old ranged from 55-57 before the program to 97-101 after the program. This group was the worst before and after the program. Overall, the results showed that a statistically significant difference was found before and after implementing the program regarding to the age of the nurses $(\mathrm{P}<0.001)$ (Table 3$)$.

In the same context, the results before the program showed that the nurses with age group between 20-24 were the best and got the highest minimum score, 68 out of 136. In addition, the nurses with 25-29 age group were the best also and got the highest maximum score (103), while the nurses 
with more than 35 years old were the worst and got the least minimum and maximum score $(55,57)$ respectively. Moreover, we found variations of nurses' improvement after the educational program regarding to all age groups: the nurses with 20-24 age group got the highest minimum score (114), the nurses with 25-29 age group got the highest maximum score (131), while the least minimum and maximum scores $(97,101)$ were for the nurses with more than 35 years respectively. Overall, this study found a statistically significant relationship of this procedure regarding to nurses' age before and after implementing the educational program $(\mathrm{p}<0.001)$ (Table 3 ).

Table 3. The description and relationship between nurses' age groups and implementation of patient care and safety measures for endotracheal suctioning procedure of the studied

\begin{tabular}{|c|c|c|c|c|c|c|}
\hline & \multirow{3}{*}{ Total score } & \multirow{2}{*}{\multicolumn{4}{|c|}{ Age of the nurse }} & \multirow{3}{*}{$\mathbf{P}$} \\
\hline & & & & & & \\
\hline & & $\begin{array}{l}20-24 \\
(n=14)\end{array}$ & $\begin{array}{l}25-29 \\
(n=17)\end{array}$ & $\begin{array}{c}30-35 \\
(n=14)\end{array}$ & $\begin{array}{c}\text { Above } 35 \\
(n=3)\end{array}$ & \\
\hline \multirow{6}{*}{ 泀 } & $\begin{array}{c}\text { Before } \\
\text { program }\end{array}$ & & & & & \\
\hline & Min. - Max. & $68.0-81.0$ & $61.0-103.0$ & $57.0-86.0$ & $55.0-57.0$ & \multirow[t]{2}{*}{$0.014^{*}$} \\
\hline & Mean \pm SD. & $75.50 \pm 3.61$ & $\begin{array}{c}76.18 \pm \\
13.76 \\
\end{array}$ & $\begin{array}{c}69.64 \pm \\
11.06 \\
\end{array}$ & $56.0 \pm 1.0$ & \\
\hline & $\begin{array}{c}\text { After } \\
\text { program }\end{array}$ & & & & & \\
\hline & Min. - Max. & $114.0-122.0$ & $113.0-131.0$ & $104.0-128.0$ & $97.0-101.0$ & \multirow{2}{*}{$\begin{array}{l}<0.001 \\
*\end{array}$} \\
\hline & Mean \pm SD. & $\begin{array}{c}118.36 \pm \\
2.21\end{array}$ & $121.0 \pm 6.26$ & $117.0 \pm 7.67$ & $99.67 \pm 2.31$ & \\
\hline
\end{tabular}

p: p value for comparing between the different studied categories *:Statistically significant at $\mathrm{p} \leq 0.05$

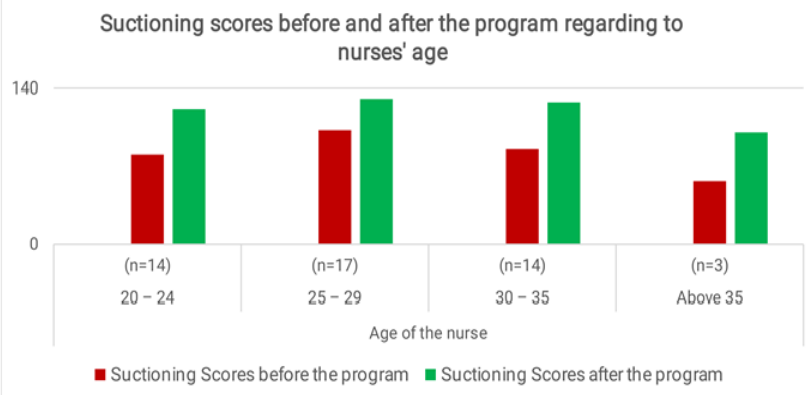

Figure 1.

\section{The Implementation of Patient Care and Safety Measures regarding to the Nurses' Qualifications}

The results above showed that the scores of nurses with diploma degree before the program varied from 55-81 out of 136 with a mean and standard deviation of $68.45 \pm 7.38$, while the nurses' scores after the program varied from 97-124 with a mean and standard deviation of $115.11 \pm 5.95$. 
The scores of nurses with a bachelor degree before the program ranged from 78-89 with a mean and standard deviation of $84.86 \pm 3.67$ into 121-130 with a mean and standard deviation of $126.86 \pm 2.97$ after the program.

The scores of nurses with a master degree before the program ranged from 97103 with a mean and standard deviation of $10.0 \pm 3.0$ into 128-131 with a mean and standard deviation of $129.67 \pm 1.53$ after the program. Overall, the results show a statistically significant relationship was found after implementing the program $(\mathrm{P}<0.001)$ (Table 4).

In the same context, the results before the educational program showed that the nurses with a master degree were the best and got the highest minimum and maximum scores $(97,103)$ respectively, while the nurses with diploma were the worst and got the least minimum and maximum scores $(55,81)$ respectively. However, we found an improvement of the nurses' scores after the educational program regarding to the different qualifications. The best performance was for the nurses with a master degree as they got the highest scores (128-131), while the worst performance was for the nurses with diploma as they got the least scores (97-124). Overall, this study found a statistically significant relationship in all steps of this procedure before and after the implementation of the educational program $(\mathrm{p}<0.001)$ (Table 4).

Table 4. The relationship between nurses' qualifications and implementation of patient care, and safety measures for endotracheal suctioning procedure of the studied nurses $(n=48)$

\begin{tabular}{|c|c|c|c|c|c|}
\hline & \multirow[t]{2}{*}{ Total score } & \multicolumn{4}{|c|}{ Qualification of the nurse } \\
\hline & & $\begin{array}{c}\text { Diploma } \\
(n=14)\end{array}$ & $\begin{array}{c}\text { Bachelor } \\
(\mathbf{n}=17)\end{array}$ & $\begin{array}{c}\text { Master } \\
(n=3)\end{array}$ & $\mathbf{P}$ \\
\hline \multirow{6}{*}{ مُ } & Before program & & & & \\
\hline & Min. - Max. & $55.0-81.0$ & $78.0-89.0$ & $97.0-103.0$ & \multirow[t]{2}{*}{$<0.001^{*}$} \\
\hline & Mean \pm SD. & $68.45 \pm 7.38$ & $84.86 \pm 3.67$ & $10.0 \pm 3.0$ & \\
\hline & After program & & & & \\
\hline & Min. - Max. & $97.0-124.0$ & $121.0-130.0$ & $128.0-131.0$ & \multirow[t]{2}{*}{$<0.001^{*}$} \\
\hline & Mean \pm SD. & $115.11 \pm 5.95$ & $126.86 \pm 2.97$ & $129.67 \pm 1.53$ & \\
\hline
\end{tabular}

$\mathrm{p}$ : p value for comparing between the different studied categories *: Statistically

significant at $\mathrm{p} \leq 0.05$

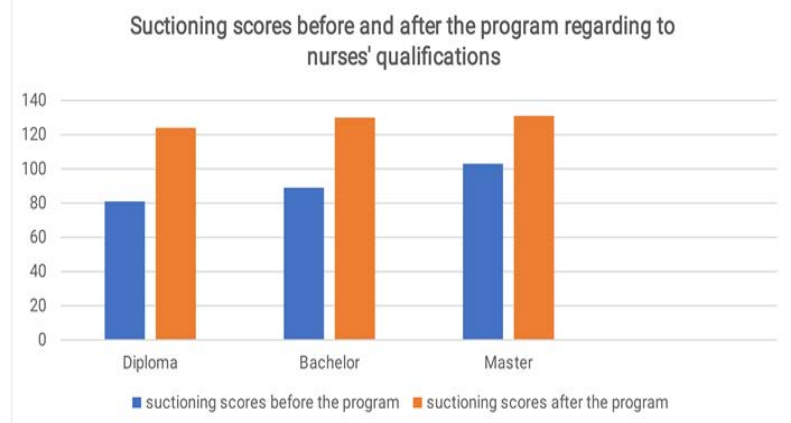

Figure 2. 


\section{The Implementation of Patient Care and Safety Measures regarding to the Nurses' Experiences}

The results above showed that the scores of nurses with less than five years of experience before the program varied from 68-103 out of 136, with a mean and standard deviation of $79.13 \pm 9.75$ into 114-131, with a mean and standard deviation of $120.91 \pm 5.04$ after the program.

The scores of nurses with five to ten years of experience before the program ranged from 57-86 with a mean and standard deviation of $70.35 \pm$ 9.74 into 109-128, with a mean and standard deviation of $118.53 \pm 5.87$ after the program.

The scores of nurses with more than ten years of experience before the program ranged from 55-65 with a mean and standard deviation of $59.88 \pm$ 3.87 into $97-116$, with a mean and standard deviation of $106.88 \pm 7.0$ after the program. Overall, the results show a statistically significant relationship was found before and after implementing the program $(\mathrm{P}<0.001)$ (Table 5).

In the same context, the results before the educational program showed that the best performance was for the nurses with less than five years of experience as they got the highest minimum and maximum scores $(68,103)$ respectively, while the worst performance was for the nurses with more than ten years of experience as they got the least minimum and maximum scores $(55,65)$ respectively. However, we found variations of nurses' improvement after the educational program regarding to all groups of nurses' experience: the nurses with less than five years of experience were the best and got the highest scores $(114,131)$, while the nurses with more than ten years of experience were the worst and got the least scores $(97,116)$. Overall, this study found a statistically significant relationship in all steps of this procedure before and after the implementation of the educational program $(\mathrm{p}<0.001)$ (Table 5).

Table 5. The relationship between nurses' experience and implementation of patient care, and safety measures for endotracheal suctioning procedure of the studied nurses $(n=48)$

\begin{tabular}{|c|c|c|c|c|c|}
\hline & \multirow[t]{2}{*}{ Total score } & \multicolumn{4}{|c|}{ Experience of the nurse in ICU } \\
\hline & & $\begin{array}{c}\text { Less than } 5 \\
\text { years }(n=14)\end{array}$ & $\begin{array}{c}\text { 5- } 10 \text { years } \\
(n=17)\end{array}$ & $\begin{array}{c}\text { More than } 10 \\
\text { years }(n=3)\end{array}$ & $\mathbf{P}$ \\
\hline \multirow{6}{*}{ 泀 } & $\begin{array}{c}\text { Before } \\
\text { program }\end{array}$ & & & & \\
\hline & Min. - Max. & $68.0-103.0$ & $57.0-86.0$ & $55.0-65.0$ & \multirow[t]{2}{*}{$<0.001^{*}$} \\
\hline & Mean \pm SD. & $79.13 \pm 9.75$ & $70.35 \pm 9.74$ & $59.88 \pm 3.87$ & \\
\hline & After program & & & & \\
\hline & Min. - Max. & $114.0-131.0$ & $109.0-128.0$ & $97.0-116.0$ & \multirow[t]{2}{*}{$<0.001^{*}$} \\
\hline & Mean \pm SD. & $120.91 \pm 5.04$ & $118.53 \pm 5.87$ & $106.88 \pm 7.0$ & \\
\hline
\end{tabular}

p: $\mathrm{p}$ value for comparing between the different studied categories *: Statistically significant at $\mathrm{p} \leq 0.05$ 


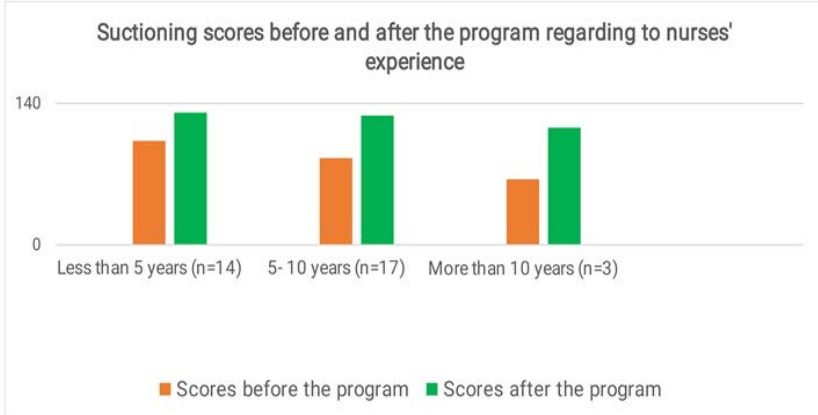

Figure 3.

\section{Discussion}

The performance of tracheal suctioning procedure is the responsibility of the critical care nurse, and she should focus on her effort to minimize any complications that can arise from this procedure (Care, 2010; Abdallh, 2018). Endotracheal suctioning is one intervention that should be based on research evidence, as there have been a large number of studies published on the various aspects of this routine procedure (Frota Loureiro et al., 2013; Ghorbanpoor Jouybari et al., 2018). The observation of tracheal suctioning procedure in this study revealed that suctioning was not implemented with complete safety measures. Moreover, many nurses neglected to apply a lot of items from this procedure to ensure the patient's safety.

The overall performance of nurses' score for tracheal suctioning ranged from 55-103 out of 136 before the educational program with a mean score of $72.81 \pm 11.37$, while after the educational program, the scores ranges from 97-131 with a mean score of $117.73 \pm 7.49$ (Table 2).

In regards to the nurses' age, the results before the educational program showed that the nurses with age group between 20-24 got the highest minimum score, 68 out of 136 . In addition, the nurses with age group between 25-29 got the highest maximum score 103, while the nurses with more than 35 years old got the least maximum and minimum scores (55-57) respectively. However, we found variations of improvement in the nurses' scores after the educational program in all age groups, the nurses with 20-24 age group got the highest minimum score 114, the nurses with 25-29 age group got the highest maximum score 131, while the nurses above 35 years got the least minimum and maximum scores (97-101) respectively. Overall, this study found a statistically significant relationship in all steps of this procedure before and after the implementation of the educational program $(p<0.001)$.

Regarding the nurses' qualifications, the results before the educational program showed that the nurses with master degree got the highest minimum and maximum scores (97-103) respectively out of 136, while the nurses with diploma got the least minimum and maximum scores (55-81) respectively. 
However, we found variations of improvement in the nurses' scores after the educational program regarding to different qualifications. The nurses with master degree got the highest scores (128-131), while the nurses with diploma got the least scores (97-124). Overall, this study found a statistically significant relationship in all steps of this procedure before and after the implementation of the educational program $(p<0.001)$.

Regarding the nurses' experience, the results before the educational program showed that the nurses with less than 5 years' experience got the highest maximum and minimum scores (68-103) respectively out of 136, while, the nurses with more than 10 years of experience got the least minimum and maximum scores (55-65) respectively. However, we found an improvement in the nurses' scores after the educational program in the different years of experience.

The nurses with less than 5 years of experience got the highest scores (114-131), while the nurses with more than 10 years of experience got the least scores (97-116). Overall, this study found a statistically significant relationship in all steps of this procedure before and after the implementation of the educational program $(\mathrm{p}<0.001)$.

The present results revealed that nurses were not following the safety measures and infection control criteria for tracheal suctioning to patients. Some nurses did not assess the following procedures: MV for mode, performing chest physiotherapy, and asses ETT/TT for cuff inflation. Therefore, this increases the possibility of patient's complications.

Our findings were in concordance with other studies (González Coscojuela et al., 2004; Amirzade Baghaei et al., 2013; Frota Loureiro et al., 2013; Leddy \& Wilkinson, 2015; Varghese \& Moly, 2016; Heidari \& Shahbazi, 2017), who reported that the level of knowledge and practice of nursing staff in endotracheal suction was average and poor, but their level of knowledge and practice increased after the training program.

Our findings are also in line with Mwakanyanga Masika et al. (2018) who reported in his study that $80.6 \%$ of the studied nurses demonstrated undesirable overall knowledge on endotracheal suctioning evidence-based recommendations. Nurses with ICU training (57.3\%) significantly demonstrated higher knowledge of ETS than non-trained nurses. Therefore, we recommend ICU training, provision of clinical guidelines and adequate support to nurses employed in ICUs.

Our findings was also supported by Sabetian and Raoufi (2015) who reported in their study that the incidence of inappropriate pressure of cuff in the tracheal tubes and tracheostomy tubes was significantly reduced after training. Also, training the nurses is highly effective in preventing VAP, particularly for appropriate cuff pressure, suctioning and disinfecting hands. In the same context, the findings of this study are also different as RN 
Thompson et al. (2007) reported that most nurses performed the skills in accordance with the best practice guideline. Nurses demonstrated a good endotracheal suctioning technique with 91\% scoring.

In addition, the results of our study are different from that of Abdallh (2018) who reported that half of responders (50\%) had good knowledge regarding infection control and near to half of responders (46.7\%) had good knowledge regarding prevention of contamination of equipment. $46.7 \%$ of responders had good knowledge regarding CDC stander precaution of infection control and 36.7\% had fair knowledge regarding transmission-based precaution. The majority (91.1\%) of the studied sample had good practice (>80\%), $77 \%$ of nurses do oral care, while $67 \%$ did not do subglottic suctioning. Less than half (47\%) of the nurses make use of hand hygiene prior suctioning, while $30 \%$ of nurses does not use facemask during suctioning the endotracheal tube. Only $10 \%$ of nurses did not perform hand hygiene after ETT suctioning. Thus, the study shows no significant relationship between education level and knowledge and practice.

\section{Conclusion and Recommendations}

In conclusion, this study assessed the effect of the teaching program on nurses' performance during endotracheal suctioning in the critical care units in Syria. Our findings highlighted that there was lack and scarcity of nurses' knowledge, and also in performance as regard the endotracheal suctioning procedure in this study. The nurses were upset because they didn't follow the protocol due to lack of training programs, too much patients, no enough time, and many other reasons. After receiving the program, the nurses were satisfied with their performance, and for receiving the new guide and protocol. There was actual and variations of improvement in nurses' knowledge and performance regarding to nurses' age, qualifications, and years of experience after receiving the program. It was recommended to help these nurses to improve their knowledge and practices. Furthermore, it is necessary to increase nurses' awareness regarding the quality of care and patient safety. The poor nurses' knowledge and practice reflects as a negative impact on quality of care and patient safety. In addition, nurses with inadequate knowledge and practice do require all the necessary support to undergo educational programs and additional training so as to improve their performances to reach the optimal quality of care and patient safety (RN Thompson et al., 2007; Sharma, Sarin et al., 2014; Ahmed, 2019).

In regards to nurses' qualifications, the best performance for providing a high quality of care was for nurses with master's degree, then nurses with bachelors, and finally nurses with diploma. Regarding to the nurses 'age, the findings showed that the nurses with age groups 20-24 and 25-29 were the best, while the nurses with more than 35 years old were the worst. On the same 
context, the findings of the present study showed that the best nurses' performance was for nurses with less than five years of experience, follow by nurses with five to ten years of experience, and finally, nurses with more than ten years of experience were the worst.

Nursing staff should focus on participating and attending the educational and training programs to improve their knowledge and performance regarding all the necessary skills and procedures needed in the intensive care units. This is aimed at providing a high quality of care for critically ill patients and to also improve patient safety. By improving these methods and giving much more educational and training support, the quality of care and safety can be improved (Ahmed, 2019; Bayatmanesh Zagheri Tafreshi et al., 2019).

On the other hand, there were lack of written policies and procedures, lack of staff training, lack of providing leadership for patient safety initiatives, lack of improving reporting systems and lack of resources, knowledge and practices of the nursing staff (Ahmed, 2019; Aziz \& Ali, 2020).

Based on the findings of the present study, the following recommendations are suggested:

- Health care organizations must develop the teaching and training programs for their staff to provide a high quality of care, promote patient safety and make them up to date.

- The nursing procedures should be done by the experienced and qualified nurses to provide high quality patient care and promote patient safety and to minimize the occurrence of hazards.

- Regular updates about the implementation of safety and prevention hazards should be provided for all critical care nurses.

- The nurse must document any serious complications that might occur.

- Developing policies and procedures related practices and the infection control practices in the intensive care unit.

\section{References:}

1. Abdallh, M. A. A. (2018). Assessment of Nurses' knowledge \& practice regarding infection control in Endotracheal intubated patient in SHARRG ELNNEEL Hospital between September-November, Saneia Ahmed Mohammed Salih.

2. Ahmed, R. E. A. (2019). Effect of Teaching Program on ICU Nurse's knowledge and Practice of Endotracheal Suctioning procedure at Omdurman military hospital (2019), Yousif Mohammed yousif.

3. Amirzade, N., et al. (2013). "Evaluating the application of safe suction criteria by nurses working in intensive care unit in Urmia." Nursing And Midwifery Journal 11(2): 0-0. 
4. Aziz, K. M. \& S. A. Ali (2020). "Determination of the Critical Care Nurses Knowledge Toward Enteral Tube Feeding in AL-Hilla Teaching Hospitals (Interventional study)." Medico Legal Update 20(1): 1153-1157.

5. Bayatmanesh, H., et al. (2019). "Patient Safety Observation by Nurses Working in the Intensive Care Units of Selected Hospitals Affiliated to Yasuj University of Medical Sciences." ISMJ 21(6): 493-506.

6. Cabrini, L., et al. (2018). "Tracheal intubation in critically ill patients: a comprehensive systematic review of randomized trials." Critical Care 22(1): 1-9.

7. Camiré, E., et al. (2009). "Medication errors in critical care: risk factors, prevention and disclosure." Cmaj 180(9): 936-943.

8. Care, A. A. F. R. (2010). "Endotracheal suctioning of mechanically ventilated patients with artificial airways 2010." Respiratory Care 55(6): 758-764.

9. Farooqi, F. I., et al. (2020). "Airway hygiene in COVID-19 pneumonia: treatment responses of 3 critically ill cruise ship employees." The American Journal of Case Reports 21: e926596926591.

10. Frota, O. P., et al. (2013). "Knowledge about endotracheal suctioning on the part of intensive care nursing professionals: a descriptive study." Online Brazilian Journal of Nursing 12(3): 546-554.

11. Ghorbanpoor, A., et al. (2018). "Knowledge and practices of nurses in intensive care units on endotracheal suctioning." Journal of Nursing Education 7(4): 9-17.

12. González, A., et al. (2004). "Assessment of practice competence and scientific knowledge of ICU nurses in the tracheal suctioning." Enfermeria intensiva 15(3): 101-111.

13. Gracia, J. E., et al. (2019). "Medication errors and drug knowledge gaps among critical-care nurses: a mixed multi-method study." BMC health services research 19(1): 1-9.

14. Griesdale, D. E., et al. (2008). "Complications of endotracheal intubation in the critically ill." Intensive care medicine 34(10): 18351842.

15. Hamilton, D. K. \&. Shepley, M. M. (2010). Design for critical care: An evidence-based approach, Routledge.

16. Heidari, M. \&. Shahbazi, S. (2017). "Nurses' awareness about principles of airway suctioning." Journal of clinical and diagnostic research: JCDR 11(8): LC17.

17. Higgs, A., et al. (2018). "Guidelines for the management of tracheal intubation in critically ill adults." British journal of anaesthesia 120(2): 323-352. 
18. Hyzy, R. C., et al. (2017). "Complications of the endotracheal tube following initial placement: Prevention and management in adult intensive care unit patients." Crit. Care Med 24: 25.

19. Jansson, M., et al. (2013). "Evaluation of endotracheal-suctioning practices of critical-care nurses-An observational correlation study." Journal of Nursing Education and Practice 3(7): 99.

20. Jones, J. \& Fix, B. (2019). Critical Care Notes Clinical Pocket Guide, FA Davis.

21. Kandeel, N. \& Tantawy, N. (2012). "Current nursing practice for prevention of ventilator associated pneumonia in ICUs." Life Science Journal 9(3): 966-973.

22. Leddy, R. \& Wilkinson, J. M. (2015). "Endotracheal suctioning practices of nurses and respiratory therapists: How well do they align with clinical practice guidelines?" Canadian journal of respiratory therapy: CJRT= Revue canadienne de la therapie respiratoire: RCTR 51(3): 60.

23. Mwakanyanga, E. T., et al. (2018). "Intensive care nurses' knowledge and practice on endotracheal suctioning of the intubated patient: A quantitative cross-sectional observational study." PloS one 13(8): e0201743.

24. Nunnery, R. K. (2019). Advancing your career: Concepts of professional nursing, FA Davis.

25. Özden, D. \& Görgülü, R. S. (2012). "Development of standard practice guidelines for open and closed system suctioning." Journal of Clinical Nursing 21(9-10): 1327-1338.

26. Peyrovi, H., et al. (2016). "Exploration of the barriers of reporting nursing errors in intensive care units: A qualitative study." Journal of the Intensive Care Society 17(3): 215-221.

27. Rezaee, N., et al. (2020). "Barriers to Providing High-Quality Nursing Care in Intensive Care Units: A Qualitative Study." Medical-Surgical Nursing Journal 9(3).

28. RN, J. C., et al. (2007). "An evaluation of the implementation of a best practice guideline on tracheal suctioning in intensive care units." International Journal of Evidence-Based Healthcare 5(3): 354-359.

29. Roberts, J. R. (2017). Roberts and Hedges' Clinical Procedures in Emergency Medicine and Acute Care E-Book, Elsevier Health Sciences.

30. Sabetian, G. \& Raoufi, S. (2015). "A comparative study of teaching clinical guideline for prevention of ventilator-associated pneumonia in two ways: face-to-face and workshop training on the knowledge and practice of nurses in the Intensive Care Unit." 
31. Sharma, S., et al. (2014). "Effectiveness of endotracheal suctioning protocol, In terms of knowledge and practices of nursing personnel." Nursing and midwifery research journal 10(2): 47-60.

32. Simpson, G., et al. (2012). "Tracheal intubation in the critically ill: a multi-centre national study of practice and complications." British journal of anaesthesia 108(5): 792-799.

33. Smith, M. C. (2019). Nursing theories and nursing practice, FA Davis.

34. Stayt, L. C. (2007). "Nurses' experiences of caring for families with relatives in intensive care units." Journal of Advanced Nursing 57(6): 623-630.

35. Varghese, S. T. \& Moly, K. (2016). "Exploratory study on the knowledge and skill of critical care nurses on endotracheal suctioning." The Journal of National Accreditation Board for Hospitals \& Healthcare Providers 3(1): 13.

36. Wilkinson, J. M., et al. (2019). Procedure checklists for Fundamentals of nursing, FA Davis. 